\title{
Immediate Effects of 2 Types of Braces on Pain and Grip Strength in People With Lateral Epicondylalgia: A Randomized Controlled Trial
}

STUDY DESIGN: Repeated-measures, crossover, double-blinded randomized controlled trial.

OBJECTIVES: To compare the immediate effectiveness of 2 types of counterforce braces in improving pain-free grip strength, pressure pain threshold, and wrist angle during a gripping task in individuals with lateral epicondylalgia.

- BACKGROUND: Sports medicine management of lateral epicondylalgia often includes application of a counterforce brace, but the comparative effectiveness of different braces is unclear. The most common brace design consists of a single strap wrapped around the proximal forearm. A variation of this brace is the use of an additional strap that wraps above the elbow, which aims to provide further unloading to the injured tissue.

METHODS: Pain-free grip strength, pressure pain threshold, and wrist angle during a gripping task were measured on 34 participants with a clinical diagnosis of lateral epicondylalgia (mean $\pm \mathrm{SD}$ age, $47.8 \pm 8.5$ years). Measurements were made without a brace, as well as immediately before and after the application of 2 types of counterforce braces. Each condition was tested during a separate session, with a minimum of 48 hours between sessions. Analysis-of-variance models were used to test the differences within and between conditions.
RESULTS: Pain-free grip strength (17.2 N; $95 \%$ confidence interval: $7.5,26.8)$ and pressure pain threshold (42.2 $\mathrm{kPa}$; $95 \%$ confidence interval: 16.5 , 68.0) significantly improved on the affected side immediately following the intervention conditions as well as the control condition. There was no significant difference between braces or the control condition for any outcome.

- CONCLUSION: Both types of counterforce braces had an immediate positive effect in participants with lateral epicondylalgia, without differences between interventions and similar to a no-brace control condition. Therefore, while the use of a brace may be helpful in managing immediate symptoms related to lateral epicondylalgia, the choice of which brace to use may be more a function of patient preference, comfort, and cost. Further research is required to investigate the comparative longer-term and clinical effects of the 2 braces. Trial registration: ACTRN12609000354280 (www.anzctr.org.au).

LEVEL OF EVIDENCE: Therapy, level $2 \mathrm{~b}$. J Orthop Sports Phys Ther 2014;44(2):120-128. Epub 9 January 2014. doi:10.2519/jospt.2014.4744

KEY WORDS: braces, lateral epicondylitis, tendinopathy, tennis elbow ateral epicondylalgia, colloquially known as "tennis elbow, is prevalent in $0.8 \%$ to $3 \%$ of the general population, ${ }^{33,39,43} 15 \%$ of those in occupations requiring repetitive hand tasks, $, 1,14,20$ and $50 \%$ of tennis players. ${ }^{1}$ Pain experienced over the lateral elbow during gripping can negatively affect daily and work tasks. ${ }^{8,20,44}$ Lateral epicondylalgia commonly involves the extensor carpi radialis brevis and common wrist extensor tendons at their proximal insertion, and more often affects the dominant side in those 35 to 55 years of age. . $15,1,3,30^{1,3}$ Clinical features of lateral epicondylalgia include decreased pain-free grip strength $(\mathrm{PFG}){ }^{35}$ hyperalgesia on palpation over the lateral epicondyle, ${ }^{35,47}$ as well as neuromuscular deficits, such as slower upper-limb reaction time ${ }^{6}$ and altered wrist posture with gripping. ${ }^{7}$

Sports medicine management of lateral epicondylalgia often involves a combination of taping, bracing, manual

${ }^{1}$ Griffith Health Institute, Griffith University, Gold Coast, Australia. ${ }^{2}$ Allied Health, Gold Coast Hospital and Health Service, Southport, Australia. ${ }^{3}$ Department of Mechanical Engineering, The University of Melbourne, Melbourne, Australia. ${ }^{4}$ Department of Physiotherapy, The University of Melbourne, Melbourne, Australia. ${ }^{5}$ School of Physiotherapy, Australian Catholic University, Sydney, Australia. The Griffith University Human Research Ethics Committee approved the research protocol for human participants. The authors received a grant in support of this research from Thermoskin (United Pacific Industries Pty Ltd, Kilsyth, Australia). The support did not include contractual or implied restriction on utilization or publication of the data and/or review of the data prior to publication. Address correspondence to Dr Leanne Bisset, Centre for Musculoskeletal Research, Griffith Health Institute, School of Allied Health Sciences, Griffith University, Gold Coast, QLD 4222 Australia. E-mail: I.bisset@griffith.edu.au ๑ Copyright @2014 Journal of Orthopaedic \& Sports Physical Therapy ${ }^{\circledR}$ 
therapy, and exercises. ${ }^{4,36}$ Clinically, bracing has been used to reduce pain severity and to assist early introduction of painfree exercise into the plan of care. Most commonly prescribed is a counterforce brace, which consists of a single strap that wraps around the proximal forearm just distal to the elbow. It is thought that the counterforce brace applies compression over the common extensor muscle mass to disperse stresses generated by muscle contraction, ${ }^{38,48}$ thereby reducing painful inhibition and allowing the patient to contract more forcefully. Furthermore, the contact of the brace with the skin and underlying tissue may facilitate muscle contraction through sensory stimulation and/or pressure to the muscle itself. $^{41}$

Also commercially available is a counterforce brace consisting of a forearm strap similar to that of the more standard counterforce brace but with an additional strap that wraps above the elbow. The purpose of this extra strap is to provide additional deloading to the lateral epicondyle by compressing and lifting the proximal aspect of the wrist extensors near their attachment on the lateral epicondyle. However, although the efficacy of counterforce braces consisting of a strap wrapped around the forearm has been evaluated in previous studies, with evidence of variable effectiveness, ${ }^{36}$ a brace consisting of an additional strap wrapping above the elbow has yet to be assessed for its ability to relieve symptoms or improve function. The primary aim of this study was to compare the immediate effectiveness of 2 types of counterforce brace, 1 with and 1 without an elbow strap, in relieving pain and improving function in people with lateral epicondylalgia.

\section{METHODS}

\section{Study Design}

A REPEATED-MEASURES, CROSSOVER, double-blinded randomized controlled trial was used, which conformed to CONSORT guidelines. ${ }^{23}$
Ethical approval was granted by the Griffith University Human Research Ethics Committee. All participants provided written informed consent prior to entry into the study.

\section{Participants}

Participants aged 18 to 67 years, with a clinical diagnosis of lateral epicondylalgia, were recruited from the community of the Gold Coast region of Queensland, Australia between June 2009 and May 2010. Volunteers responded to advertisements in print media, as well as notices in university staff and student newsletters. An experienced physiotherapist performed all screening assessments to determine eligibility, using clinical presentation criteria consistent with previous studies. ${ }^{4,11}$ Clinical diagnostic criteria for lateral epicondylalgia are considered the gold standard, as the correlation of imaging with symptoms is variable in lateral epicondylalgia. ${ }^{17,21,28,46}$

Volunteers were eligible for inclusion if they had pain over the lateral elbow for a minimum of 6 weeks that increased with palpation of the lateral epicondyle, gripping, or resisted extension of the wrist or the second or third finger. $.^{15} \mathrm{Ex}-$ clusion criteria included bilateral elbow symptoms; cervical radiculopathy; any other elbow joint pathology or peripheral nerve involvement; past history of elbow surgery, dislocation, fracture, or tendon rupture; shoulder, wrist, or hand pathology; systemic or neurological disorders; treatment for elbow pain by a health care practitioner within the preceding 3 months; and corticosteroid injection for elbow pain within the previous 6 months. In light of the lack of firm diagnostic accuracy in excluding cervical spine or neural factors as the primary source of elbow pain, we took a clinical-reasoning approach based on the participant history (negative likelihood ratio [-LR] range, 0.5-1.1), neurological exam (-LR range, 0.12-1.16), upper-limb neural provocation test $(-\mathrm{LR}=0.85)$, and cervical rotation range of movement (-LR range, $0.23-0.27)^{42}$

\section{Sample Size}

Based on estimates of between-group differences from a previous study of similar design, ${ }^{40}$ to detect significant mean $\pm \mathrm{SD}$ differences of $33 \pm 60 \mathrm{kPa}$ in pressure pain threshold (PPT) and $27 \pm 44 \mathrm{~N}$ in PFG, at $90 \%$ power $(\alpha=.05)$, a sample size of 35 was required. This sample size would also provide $90 \%$ power $(\alpha=.05)$ with an effect size of 0.2 and 0.8 correlation among repeated measures $\left(\mathrm{G}^{*}\right.$ Power Version 3.1.3; Heinrich-Heine University, Düsseldorf, Germany). The sample size was not adjusted to account for dropouts, based on there being no loss to follow-up in previous studies of similar design. ${ }^{26,40}$

\section{Outcome Measures}

Outcome measures were taken by a blinded assessor skilled in their application and were performed on both the affected and unaffected sides preintervention and postintervention. The primary outcome was PFG, measured using a digital analyzer grip dynamometer (MIE Medical Research Ltd, Leeds, UK). Participants were positioned in sitting, with their test arm at $90^{\circ}$ of shoulder flexion, elbow fully extended, and wrist pronated. A gutter splint was positioned under the elbow to allow the wrist and hand to adopt a spontaneous posture during the gripping task. Participants were instructed to squeeze the dynamometer, slowly increasing the force until the first onset of pain. ${ }^{35}$ The assessor manually recorded the maximum force output displayed on the screen. This was repeated 3 times, with an intervening 30-second rest interval, and the average of 3 measures was calculated. PFG measurements have previously been shown to be reliable (intratester intraclass correlation coefficient [ICC $]=0.96 ; 95 \%$ confidence interval [CI]: $0.92,0.98)$ in individuals with lateral epicondylalgia. ${ }^{12}$

In light of preliminary evidence suggesting that wrist posture during a gripping task may be altered in people with lateral epicondylalgia, ${ }^{7}$ we chose to include sagittal plane wrist angle dur- 
ing PFG as a secondary outcome. A 3-D motion-tracking sensor (MTi; Xsens Technologies BV, Enschede, the Netherlands) was placed on the dorsal aspect of the hand and secured with Velcro (Velcro USA Inc, Manchester, NH). Neutral wrist flexion/extension was identified as $0^{\circ}$ by the software, with the palmar aspect of the hand and pronated forearm placed flat on a table and the software calibrated prior to data collection. Wrist-angle data during each PFG test were recorded using LabVIEW software (Version 8.5; National Instruments Corporation, Austin, TX) and exported into Microsoft Excel (Microsoft Corporation, Redmond, WA) for processing. The mean angle for wrist flexion/extension across the 3 gripping efforts was calculated, with positive scores indicating wrist extension.

Pressure algometry was also used as a secondary outcome to measure PPT. PPT measurements have good intratester reliability in individuals with lateral epicondylalgia, with an ICC of 0.76 (95\% CI: $0.56,0.89$ ) on the affected side. ${ }^{12}$ The most sensitive point over the lateral humeral epicondyle was located by manual palpation and marked with a permanent marker, to ensure that the same site was used for preintervention and postintervention measures. Pressure was applied at a consistent rate $(40 \mathrm{kPa} / \mathrm{s})$ over the lateral epicondyle via a pressure algometer (1- $\mathrm{cm}^{2}$ tip, load cell, switch, dataacquisition card, and LabVIEW Version 8.5 software). The participant was instructed to activate a switch when the sensation of pressure first changed to one of pressure and pain. The corresponding pressure value $\left(\mathrm{kPa} / \mathrm{cm}^{2}\right)$ was saved in LabVIEW. Three repeat measures were taken, with a 30-second rest between each measurement, and the average was calculated.

In addition, clinical characteristics were recorded at baseline, including a condition-specific validated self-report questionnaire of pain and disability (Patient-Rated Tennis Elbow Evaluation, with a score ranging from 0 to 100,0 in-

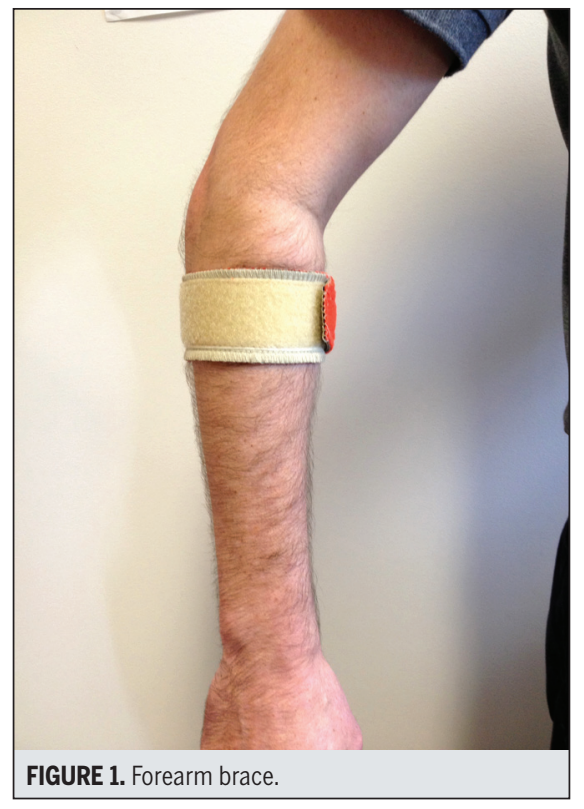

dicating no pain or disability and 100 the worst imaginable pain and disability), ${ }^{24,29}$ severity of current resting pain and worst pain over the preceding week using a $100-\mathrm{mm}$ visual analog scale, and average level of function over the preceding week using a 100-mm visual analog scale.

\section{Intervention Conditions}

All intervention conditions were applied to the affected elbow by an experienced physiotherapist. A commercially available counterforce brace (Thermoskin tennis elbow strap with pad; United Pacific Industries Pty Ltd, Kilsyth, Australia) was used, which consisted of a strap applied circumferentially around the proximal forearm, just distal to the lateral epicondyle (forearm-brace condition) (FIGURE 1). This brace was compared to another commercially available counterforce brace (Go-Strap; Sportstek Physical Therapy Supplies Pty Ltd, Oakleigh, Australia), consisting of a similar strap applied around the proximal forearm but with an additional strap that passed from the lateral aspect of the brace, anterior to the lateral epicondyle, and around the posterior and medial aspects of the distal humerus, then attached back onto the counterforce brace laterally (forearm-elbow-brace condition) (FIGURE 2).

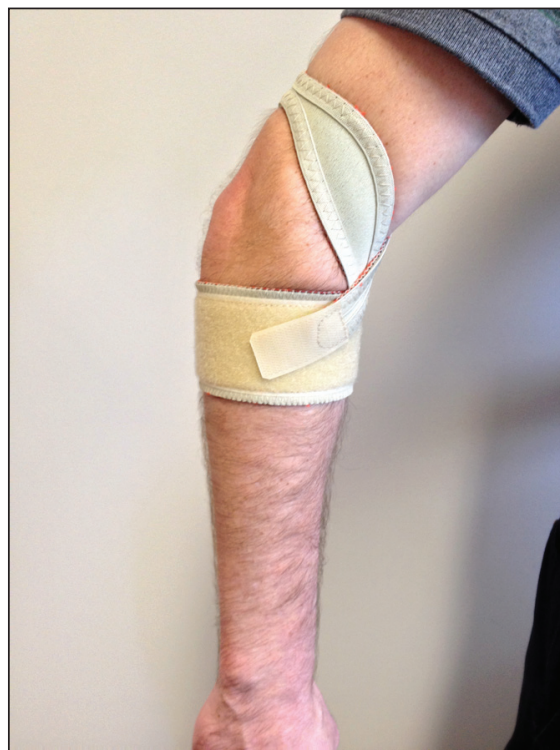

FIGURE 2. Forearm-elbow brace, consisting of a standard counterforce brace with the additional strap wrapping above the elbow.

Both braces were applied according to the manufacturer's recommendations to ensure correct fitting. The physiotherapist applied sufficient tension to ensure that the brace felt supportive when performing light gripping, but was comfortable. For the no-brace condition, the participant was positioned for the same length of time in the laboratory with the treating physiotherapist, with no brace applied.

\section{Procedure}

Participants attended 3 testing sessions in a university laboratory, with at least 48 hours between each session to minimize the carryover effects between interventions. During the testing period, participants were requested to avoid factors that may influence their elbow pain, such as analgesics and anti-inflammatory medication. Each session commenced with a blinded assessor performing outcome measures on both the affected and unaffected sides in a randomized order. This assessor remained blind to treatment allocation throughout the study period.

An experienced physiotherapist, who was blinded to all outcome measures, applied 1 of 3 intervention conditions 


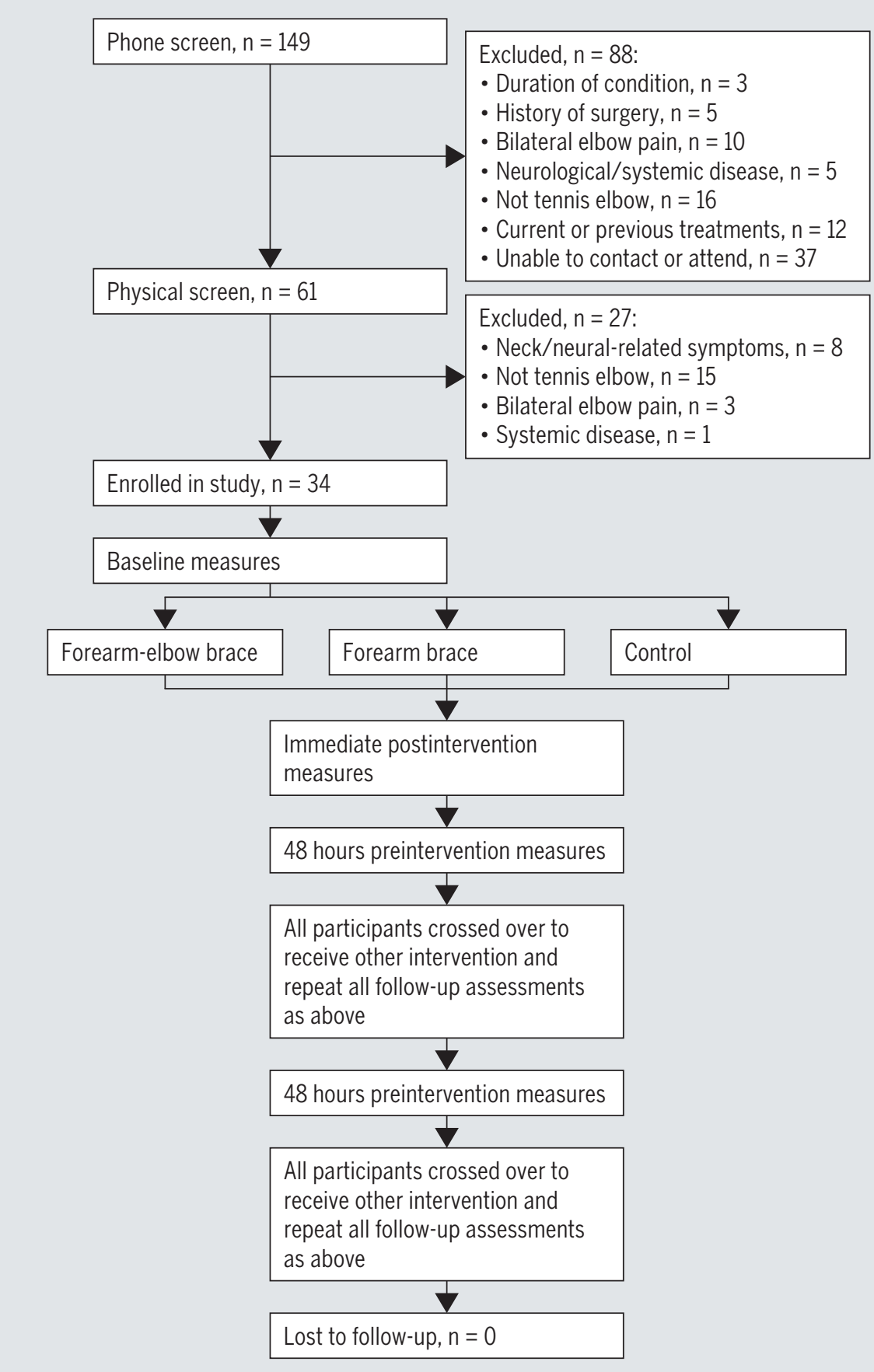

FIGURE 3. Flow of participants through the study.

in randomized order: forearm brace, forearm-elbow brace, no brace. The computer-generated randomization sequence, created by an investigator who was not involved with either treatment or outcome assessment, was delivered via sealed, opaque envelopes, which were held by the treating therapist and opened in consecutive order.

Participant blinding was facilitated by visually obstructing the participant's view while each intervention was applied, and by not disclosing the purpose of each brace. Following application of each con- dition, opaque fabric was draped over the arm and forearm, covering the brace straps and leaving only the lateral epicondyle visible for measure of PPT. This ensured maintenance of assessor and participant blinding. The blinded assessor then repeated the PFG, wrist angle, and PPT measures with the test condition in situ. Due to the location of the braces, PPT was applied above the forearm brace and between the top and bottom straps of the forearm-elbow brace. The arm was also covered and measures taken immediately following the control condition. At the conclusion of each test session, assessor blinding was examined via a questionnaire. Participants were also questioned at the conclusion of the study regarding their condition preference.

\section{Statistical Analysis}

Statistical analyses were performed on an intention-to-treat basis using SPSS software (Version 19.0; SPSS Inc, Chicago, IL), with an alpha set at $P<.05$. ICC and the standard error of measurement (standard deviation $\times \sqrt{1-\text { ICC) }}$ were calculated from the 3 trials to determine intratester within-session reliability and magnitude of measurement error, respectively, for each dependent variable (PFG, wrist angle, PPT) at baseline. In addition, we calculated the minimal detectable change $(1.96 \times \sqrt{2} \times$ standard error of measurement) to ensure with $95 \%$ confidence that the true value of the measure was contained within this range. ${ }^{3}$

To assess the similarity between precondition measures collected at the beginning of each of the 3 testing sessions, a 2-way, repeated-measures analysis of variance was used, with side (affected, unaffected) and condition (forearm brace, forearm-elbow brace, control) included as independent variables for each outcome (PFG, wrist angle, PPT). Given that the condition was only applied to the affected elbow, each side was analyzed separately to determine the effect of the condition over time, using repeated-measures general linear models, with time (preintervention, postintervention) and 


\begin{tabular}{|c|c|c|}
\hline \multicolumn{3}{|c|}{ Baseline Participant Characteristics $(\mathbf{N}=34)^{\circ}$} \\
\hline Participant Characteristics & Values & $\mathrm{MDC}_{95}$ \\
\hline Male, $n(\%)$ & $18(52.9)$ & \\
\hline Age, y & $47.8 \pm 8.5(28-67)$ & \\
\hline \multicolumn{3}{|l|}{ Employment status, $n(\%)$} \\
\hline Manual labor & $7(20.6)$ & \\
\hline Nonmanual labor & $25(73.5)$ & \\
\hline Not employed & $2(5.9)$ & \\
\hline Right side dominant, n (\%) & $31(91.2)$ & \\
\hline Dominant side affected, $\mathrm{n}(\%)$ & $28(82.4)$ & \\
\hline Duration of condition, wk & $64.6 \pm 137.4(6-570)$ & \\
\hline Recurrent condition, $\mathrm{n}(\%)$ & $9(26.5)$ & \\
\hline $\mathrm{PRTEE}^{\dagger}$ & $38.7 \pm 15.0(11-69)$ & \\
\hline Average function in the past wk $k^{\ddagger}$ & $76.0 \pm 22.5(5-100)$ & \\
\hline Worst pain in past week ${ }^{\ddagger}$ & $57.8 \pm 21.1(19-100)$ & \\
\hline Resting pain ${ }^{\ddagger}$ & $16.0 \pm 14.6(0-60)$ & \\
\hline \multicolumn{3}{|l|}{ Affected side } \\
\hline Pain-free grip, N & $117.7 \pm 69.7(23.3-250.3)$ & 40.1 \\
\hline Pressure pain threshold, $\mathrm{kPa}$ & $403.1 \pm 146.3(147.4-816.7)$ & 134.3 \\
\hline Wrist angle during gripping, deg & $29.6 \pm 8.9(9.3-49.4)$ & 6.3 \\
\hline \multicolumn{3}{|l|}{ Unaffected side } \\
\hline Pain-free grip, $N$ & $288.6 \pm 94.5(125-565.7)$ & 40.8 \\
\hline Pressure pain threshold, $\mathrm{kPa}$ & $720.1 \pm 195.7(263.8-1178.9)$ & 214.9 \\
\hline Wrist angle during gripping, deg & $34.5 \pm 8.9(12.3-54.4)$ & 5.2 \\
\hline \multicolumn{3}{|c|}{$\begin{array}{l}\text { Abbreviations: } M D C_{95} \text {, minimal detectable change at } 95 \% \text { confidence; PRTEE, Patient-Rated Tennis } \\
\text { Elbow Evaluation. } \\
{ }^{*} \text { Values are mean } \pm S D \text { (range) unless otherwise indicated. } \\
{ }^{+} \text {O to } 100 \text { points, where } 100 \text { is maximal disability. } \\
{ }^{+} 100-\text { - } m \text { m visual analog scale, where } O \text { is no pain/disability and } 100 \text { is worst pain/disability. }\end{array}$} \\
\hline
\end{tabular}

condition as independent variables. Post hoc testing using paired $t$ tests $(P<.05)$ was conducted if the omnibus analyses reported significant interaction or main effects. In the presence of significant interaction or main effects, the betweenand/or within-condition effect size was expressed as Cohen $d$, with less than 0.5 considered a small effect, between 0.5 and 0.8 a moderate effect, and greater than 0.8 a large effect. ${ }^{10}$

\section{RESULTS}

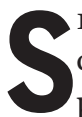
XTY-ONE VOLUNTEERS WERE PHYSIcally screened for inclusion, with 34 participants enrolled in the study (FIGURE 3). All participants received the conditions as per the randomization schedule, and there were no losses to follow-up. Participant demographics, baseline outcome measures, and measurement error (MDC) are reported in TABLE 1. To be confident that any change in PFG and PPT on the affected side was real and not related to measurement error, we calculated that a change greater than $40 \mathrm{~N}$ for PFG, $135 \mathrm{kPa}$ for PPT, and $6.3^{\circ}$ for wrist angle would be required.

\section{Reliability}

Intratester reliability for PFG (ICC = $0.945 ; 95 \% \mathrm{CI}: 0.902,0.971)$, PPT $(\mathrm{ICC}=0.935 ; 95 \% \mathrm{CI}: 0.884,0.966)$, and wrist angle (ICC $=0.935 ; 95 \% \mathrm{CI}$ : $0.884,0.966)$ on the affected side was excellent, ${ }^{27}$ as was reliability on the unaffected side $(\mathrm{PFG}, \mathrm{ICC}=0.975 ; \mathrm{PPT}$, $\mathrm{ICC}=0.901$; and wrist angle, $\mathrm{ICC}=$ 0.956).

\section{Precondition}

There was no significant interaction (condition by side) or main effect of condition for any precondition outcome, indicating no difference between measures taken at the beginning of each testing session for either the affected or unaffected side. This confirms that the time between appointments was sufficient to have a washout effect and restore baseline levels between conditions (TABLE 2). There was, however, a significant difference between affected and unaffected sides for all outcomes. Compared with the unaffected side, the affected side produced $170.9 \mathrm{~N}$ lower PFG (95\% CI: 142.7, 199.0 N), 317 $\mathrm{kPa}$ lower PPT (95\% CI: 247.8, 386.3 $\mathrm{kPa})$, and $5.0^{\circ}$ less wrist extension $(95 \%$ CI: $2.0^{\circ}, 8.0^{\circ}$ ).

\section{Conditions}

There were no adverse events reported by participants during the study. There was no significant condition-by-time interaction on the affected side for PFG $(P=.07)$, PPT $(P=.48)$, or wrist angle $(P=.2)$. There was a significant main effect for time $(P=.001)$ but not condition $(P=.1)$ for PFG on the affected side. At post hoc testing, the affected side demonstrated a small improvement of $17.2 \mathrm{~N}$ in PFG (effect size, $0.2 ; 95 \% \mathrm{CI}$ : $7.5,26.8 \mathrm{~N}$ ), regardless of the intervention condition. There was no significant change in PFG on the unaffected side, either over time or between conditions (TABLE 2).

Consistent with PFG, PPT also demonstrated a significant main effect for time $(P=.002)$ but not condition $(P=$ $.9)$ on the affected side, with a mean improvement of $42.2 \mathrm{kPa}$ (effect size, 0.2 ; $95 \% \mathrm{CI}: 16.5,68.0 \mathrm{kPa}$ ) from precondition to postcondition. The unaffected side remained unchanged between conditions $(P=.4)$; however, the change over time approached significance (mean difference from precondition to postcondition, $29 \mathrm{kPa} ; 95 \% \mathrm{CI}:-1.2$, $59.6 \mathrm{kPa} ; P=.06)$.

The only significant difference in wrist angle was precondition to postcondition 


\section{TABLE 2}

\begin{tabular}{|c|c|c|c|c|c|c|}
\hline & Control & Forearm-Elbow & Forearm & $\begin{array}{c}\text { Forearm-Elbow - } \\
\text { Forearm }\end{array}$ & $\begin{array}{c}\text { Forearm-Elbow - } \\
\text { Control }\end{array}$ & Forearm - Control \\
\hline \multicolumn{7}{|l|}{ Affected side } \\
\hline Preintervention & $110.0 \pm 66.7$ & $112.8 \pm 70.7$ & $130.1 \pm 103.6$ & & & \\
\hline Postintervention & $117.4 \pm 61.5$ & $135.0 \pm 82.8$ & $152.0 \pm 114.1$ & & & \\
\hline Mean difference ${ }^{\dagger}$ & $7.3(-1.5,16.0)$ & $22.2(8.4,36.0)$ & $21.9(9.1,34.6)$ & $0.4(-15.7,16.4)$ & $15.0(0.6,29.3)$ & $14.6(0.0,29.2)$ \\
\hline Preintervention & $30.0 \pm 6.4$ & $28.9 \pm 8.8$ & $28.9 \pm 10.1$ & & & \\
\hline Postintervention & $29.4 \pm 7.4$ & $28.3 \pm 8.2$ & $30.6 \pm 9.2$ & & & \\
\hline Mean difference ${ }^{\dagger}$ & $-1.2(-3.6,1.3)$ & $-0.7(-3.0,1.7)$ & $1.5(-0.8,3.8)$ & $-2.2(-5.2,0.9)$ & $0.5(-3.0,4.0)$ & $2.6(-0.3,5.5)$ \\
\hline \multicolumn{7}{|l|}{ PPT, kPa } \\
\hline Preintervention & $408.2 \pm 176.8$ & $403.3 \pm 164.8$ & $397.8 \pm 184.7$ & & & \\
\hline Preintervention & $291.8 \pm 92.5$ & $287.4 \pm 96.5$ & $286.4 \pm 99.5$ & & & \\
\hline Postintervention & $287.6 \pm 102.3$ & $290.7 \pm 94.2$ & $287.5 \pm 95.8$ & & & \\
\hline Mean difference ${ }^{\dagger}$ & $-4.5(-13.6,4.5)$ & $3.3(-4.8,11.5)$ & $1.0(-11.4,13.4)$ & $2.3(-9.2,13.7)$ & $7.8(-20.2,4.5)$ & $5.6(-9.3,20.4)$ \\
\hline \multicolumn{7}{|c|}{ Wrist angle during PFG, deg } \\
\hline Preintervention & $36.0 \pm 8.9$ & $33.5 \pm 9.3$ & $34.7 \pm 8.8$ & & & \\
\hline Postintervention & $37.1 \pm 9.2$ & $36.7 \pm 8.0$ & $36.3 \pm 8.4$ & & & \\
\hline Mean difference ${ }^{\dagger}$ & $1.1(-1.0,3.1)$ & $2.9(0.5,5.3)$ & $1.6(-0.7,3.8)$ & $1.1(-2.1,4.3)$ & $1.8(-1.4,5.1)$ & $0.1(-3.4,3.7)$ \\
\hline \multicolumn{7}{|l|}{ PPT, kPa } \\
\hline Preintervention & $717.4 \pm 236.2$ & $707.3 \pm 217.6$ & $735.6 \pm 229.1$ & & & \\
\hline Postintervention & $712.5 \pm 244.5$ & $651.9 \pm 208.4$ & $708.3 \pm 258.6$ & & & \\
\hline
\end{tabular}

on the unaffected side $(P=.004)$; however, the difference was small $\left(1.7^{\circ} ; 95 \%\right.$ CI: $0.6^{\circ}, 2.7^{\circ}$ ) and not meaningful, based on the MDC of $5.2^{\circ}$ (TABLE 1).

\section{Blinding}

The assessor guessed the correct intervention condition on 39 of 102 (38\%) occasions. Specifically, the assessor correctly guessed the use of the forearm-elbow brace on 14 ( $41 \%$ ) occasions, the use of the forearm brace on 15 (44\%) occasions, and the control condition on $10(30 \%)$ occasions. At the end of the study, 21 (62\%), 11 $(32 \%)$, and $2(6 \%)$ participants reported a preference for the forearm-elbow-brace, forearm-brace, and control (no-brace) conditions, respectively.

\section{DISCUSSION}

$T$ HIS STUDY SHOWED THAT THERE was a small but statistically significant immediate improvement in PFG strength and PPT preintervention to postintervention on the affected side, but this improvement did not discriminate between the brace and control conditions. Regardless of the bracing intervention, minimum improvements of 17.2 N in PFG and 42.2 kPa in PPT were achieved on the affected side. However, the improvements in PFG and PPT reported in this study are smaller than the MDCs, and may therefore be due to measurement error rather than a true clinical change. Furthermore, the change in PPT on the unaffected side approached statistical significance $(P=.06)$, which may reflect a lack of statistical power (ie, insufficient sample size). We should note that this study only measured immediate effects, and it may be that a larger change in outcomes on the affected side occurs with increased time spent in the brace.

Our findings are somewhat consistent with a number of other studies that have investigated the effect of bracing on grip 
and pain in lateral epicondylalgia. These studies, with various degrees of rigor, ${ }^{5}$ have assessed the effectiveness of a variety of elbow braces against other currently accepted treatments or placebo/ control. Overall, despite variations in study designs, timing of outcomes, type of brace, and comparator groups, ${ }^{5}$ most studies have shown that elbow or forearm braces improve pain and function in people with lateral epicondylalgia. . $^{2,13,18,32}$ Although the results of our study found an improvement between prebracing and postbracing measures, overall, the brace conditions were no more effective than the control at improving immediate outcomes. As such, it appears that the additional strap on the forearm-elbow brace does not improve the efficacy of the existing forearm brace to immediately relieve pain or improve function.

It is hypothesized that the mechanism by which the forearm brace exerts its clinical efficacy is by decreasing the muscle and tendon forces acting at the lateral epicondyle, thereby offloading the site of pain. There is some evidence to support this theory. Studies have shown a $46 \%$ decrease in acceleration amplitudes at the lateral epicondyle with the use of a forearm brace with a silicon pad, ${ }^{45}$ decreased electromyographic activity in the wrist extensors with both the standard and air-pillow forearm braces, ${ }^{34}$ and decreased strain at the origin of the extensor carpi radialis brevis muscle when a forearm brace was applied. ${ }^{37,38}$ If this mechanism of action is accepted, then by association with our outcomes, the additional strap located on the forearmelbow brace does not appear to enhance this muscle-tendon deloading.

In contrast, the effect of bracing on neuromuscular performance in lateral epicondylalgia is less convincing. The current study found that neither brace significantly influenced the angle of wrist extension spontaneously adopted during the pain-free gripping task. In fact, a previous study ${ }^{25}$ found that bracing may adversely affect wrist joint position error but may have no effect on stretch latency of the extensor carpi ulnaris. Interestingly, we did identify a significant difference in wrist angle between sides, with the affected side gripping with approximately $5^{\circ}$ less wrist extension than the unaffected side. This has implications for the performance of everyday activities, as gripping with a flexed wrist posture has been shown to be inefficient in producing maximum grip force in normal populations. ${ }^{19,22}$ As our lateral epicondylalgia cohort did still grip with some degree of wrist extension, further research is required to investigate the contribution of wrist posture to muscle activity and the relationship between wrist angle and other symptoms in people with lateral epicondylalgia. However, these findings may help to explain some of the symptoms experienced by those with lateral epicondylalgia, such as weakness during gripping tasks.

To our knowledge, this is the first study to identify side-to-side differences in wrist extension angle during gripping in individuals with unilateral lateral epicondylalgia. A previous paper ${ }^{7}$ found that those with lateral epicondylalgia gripped with $11^{\circ}$ less wrist extension than an ageand gender-matched healthy control cohort; however, the authors found no difference between sides within groups. This difference in results between studies might be due to the equipment used. The previous study ${ }^{7}$ used digital photographs and computer software to measure wrist extension angle, whereas the present study used a 3-D motion-tracking sensor. It is possible that the level of error in the photographic technique was higher than the error using the motion sensor. Limits of agreement using the digitalimage technique compared to a universal goniometer have been reported at $-1.9^{\circ}$ to $1.8^{\circ}$ for knee flexion, ${ }^{31}$ whereas the manufacturers of the MTi device (Xsens Technologies BV) report a static accuracy of less than $0.5^{\circ}$. Therefore, it is plausible that the lower measurement error associated with the motion sensor allowed identification of side differences within our lateral epicondylalgia popula- tion that previously went unseen.

While this is the first study, to our knowledge, to evaluate the immediate effects of the forearm-elbow brace compared to the forearm brace in lateral epicondylalgia, there are limitations that must be acknowledged. The physiotherapist applied the braces in a manner reflective of clinical practice, ensuring that the brace felt supportive but comfortable. Although the physiotherapist attempted to apply the braces with consistent tension on the straps, it is possible that the level of tension varied between applications, as this was not quantified. However, considering that brace tension does not appear to influence wrist extension strength, ${ }^{25}$ it is unlikely to have influenced the PFG measures. Though the use of analgesic and anti-inflammatory medication was not controlled in this study, it is unlikely to have improved the results, as analgesia would minimize the change between baseline and postcondition measures, providing a more conservative estimate of effect. Furthermore, we attempted to blind participants (and the assessor) to the type of brace by not revealing the difference between the 2 braces, by applying a blindfold while the braces were applied, and by draping the limb that covered the arm, except for a small area through which the PPT measures could be taken. It appears that the assessor blinding was not completely successful, as the assessor correctly guessed the intervention on more occasions than would be expected by chance alone. Approximately $60 \%$ of participants preferred the forearm-elbow brace, suggesting that, while these results do not support the use of one brace over another, participants' choice of brace may be based on features other than random selection. Furthermore, while patients typically wear an elbow brace to improve pain-free function, the impact of the test braces on general upper-limb function was not assessed in this study. Finally, this study only evaluated the immediate effects of the forearm braces, with no longer-term follow-up. This should be addressed in future studies of brace 
effectiveness. Nevertheless, considering that the application of a forearm brace is expected to have an immediate effect on symptoms and is rarely applied in isolation in the clinical setting, the evaluation of the braces' immediate effects was believed to be most clinically relevant as an initial stage in comparing effectiveness.

\section{CONCLUSION}

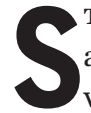
TATISTICALLY SIGNIFICANT IMMEDIate improvements in PFG and PPT were identified in individuals with lateral epicondylalgia, preapplication to postapplication of a forearm brace, a forearm-elbow brace, and no brace (control condition), with no difference found between conditions. The improvements in outcomes may be due to measurement error rather than true clinical change. As neither brace appeared to provide superior immediate benefits, decisions regarding their use in clinical practice should not be based on type, but rather on other factors such as patient preference, comfort, and cost. Further research is required to investigate longer-term effects and improve our understanding of the significance of neuromotor deficits, such as wrist angle with gripping, in lateral epicondylalgia. 0

\section{KEY POINTS}

FINDINGS: The application of a forearm brace or a forearm-elbow brace has an immediate positive effect on grip strength and pain in people with lateral epicondylalgia, although this improvement may be a function of measurement error, as reflected by a similar improvement in the control condition. There was no difference in outcomes between the braces tested.

IMPLICATIONS: The choice of brace should not be based on the brace type but, rather, on other factors, such as patient preference, comfort, and cost. CAUTION: The improvements identified in this study may be due to measurement error. The long-term effectiveness of braces requires further investigation.
ACKNOWLEDGEMENTS: We thank Mr Neil Motyer, inventor of the forearm-elbow brace, for supplying and advising on use of the brace, which is now manufactured as the Go-Strap by Sportstek Physical Therapy Supplies Pty Ltd, Oakleigh, Australia, and United Pacific Industries Pty Ltd, Kilsyth, Australia, for supply of the forearm counterforce brace.

\section{REFERENCES}

1. Abrams GD, Renstrom PA, Safran MR. Epidemiology of musculoskeletal injury in the tennis player. Br J Sports Med. 2012;46:492-498. http://dx.doi.org/10.1136/bjsports-2012-091164

2. Altan L, Kanat E. Conservative treatment of lateral epicondylitis: comparison of two different orthotic devices. Clin Rheumatol. 2008;27:1015-1019. http://dx.doi.org/10.1007/ s10067-008-0862-8

3. Bialocerkowski A, Klupp N, Bragge P. How to read and critically appraise a reliability article. Int J Ther Rehabil. 2010;17:114-120.

4. Bisset L, Beller E, Jull G, Brooks P, Darnell R, Vicenzino B. Mobilisation with movement and exercise, corticosteroid injection, or wait and see for tennis elbow: randomised trial. BMJ. 2006:333:939. http://dx.doi.org/10.1136/ bmj.38961.584653.AE

5. Bisset L, Paungmali A, Vicenzino B, Beller E. A systematic review and meta-analysis of clinical trials on physical interventions for lateral epicondylalgia. Br J Sports Med. 2005;39:411-422. http://dx.doi.org/10.1136/bjsm.2004.016170

6. Bisset LM, Coppieters MW, Vicenzino B. Sensorimotor deficits remain despite resolution of symptoms using conservative treatment in patients with tennis elbow: a randomized controlled trial. Arch Phys Med Rehabil. 2009;90:18. http://dx.doi.org/10.1016/j.apmr.2008.06.031

7. Bisset LM, Russell T, Bradley S, Ha B, Vicenzino BT. Bilateral sensorimotor abnormalities in unilateral lateral epicondylalgia. Arch Phys Med Rehabil. 2006;87:490-495. http://dx.doi. org/10.1016/j.apmr.2005.11.029

8. Bot SD, van der Waal JM, Terwee CB, et al. Incidence and prevalence of complaints of the neck and upper extremity in general practice. Ann Rheum Dis. 2005;64:118-123. http://dx.doi. org/10.1136/ard.2003.019349

9. Chiang HC, Ko YC, Chen SS, Yu HS, Wu TN, Chang PY. Prevalence of shoulder and upperlimb disorders among workers in the fish-processing industry. Scand J Work Environ Health. 1993;19:126-131.

10. Cohen J. Statistical Power Analysis for the Behavioral Sciences. 2nd ed. Hillsdale, NJ: Lawrence Erlbaum Associates; 1988.

11. Coombes BK, Bisset L, Brooks P, Khan A, Vicenzino B. Effect of corticosteroid injection, physiotherapy, or both on clinical outcomes in patients with unilateral lateral epicondylalgia: a randomized controlled trial. JAMA. 2013;309:461-469. http://dx.doi.org/10.1001/jama.2013.129

12. Fernández-Carnero J, Cleland JA, Arbizu RL. Examination of motor and hypoalgesic effects of cervical vs thoracic spine manipulation in patients with lateral epicondylalgia: a clinical trial. J Manipulative Physiol Ther. 2011;34:432-440. http://dx.doi.org/10.1016/j.jmpt.2011.05.019

13. Garg R, Adamson GJ, Dawson PA, Shankwiler JA, Pink MM. A prospective randomized study comparing a forearm strap brace versus a wrist splint for the treatment of lateral epicondylitis. J Shoulder Elbow Surg. 2010;19:508-512. http:// dx.doi.org/10.1016/j.jse.2009.12.015

14. Gold JE, d'Errico A, Katz JN, Gore R, Punnett L. Specific and non-specific upper extremity musculoskeletal disorder syndromes in automobile manufacturing workers. Am J Ind Med. 2009;52:124-132. http://dx.doi.org/10.1002/ ajim. 20653

15. Haker E. Lateral epicondylalgia: diagnosis, treatment and evaluation. Crit Rev Phys Rehabil Med. 1993;5:129-154.

16. Hamilton PG. The prevalence of humeral epicondylitis: a survey in general practice. J R Coll Gen Pract. 1986;36:464-465.

17. Harrington JM, Carter JT, Birrell L, Gompertz D. Surveillance case definitions for work related upper limb pain syndromes. Occup Environ Med. 1998;55:264-271.

18. Jafarian FS, Demneh ES, Tyson SF. The immediate effect of orthotic management on grip strength of patients with lateral epicondylosis. J Orthop Sports Phys Ther. 2009;39:484-489. http://dx.doi.org/10.2519/jospt.2009.2988

19. Kraft GH, Detels PE. Position of function of the wrist. Arch Phys Med Rehabil. 1972;53:272-275.

20. Kurppa K, Viikari-Juntura E, Kuosma E, Huuskonen M, Kivi P. Incidence of tenosynovitis or peritendinitis and epicondylitis in a meat-processing factory. Scand J Work Environ Health. 1991;17:32-37.

21. Levin D, Nazarian LN, Miller TT, et al. Lateral epicondylitis of the elbow: US findings. Radiology. 2005;237:230-234. http://dx.doi.org/10.1148/ radiol.2371040784

22. Mogk JP, Keir PJ. The effects of posture on forearm muscle loading during gripping. Ergonomics. 2003;46:956-975. http://dx.doi. org/10.1080/0014013031000107595

23. Moher D, Hopewell S, Schulz KF, et al. CONSORT 2010 explanation and elaboration: updated guidelines for reporting parallel group randomised trials. Int J Surg. 2012;10:28-55. http:// dx.doi.org/10.1016/j.ijsu.2011.10.001

24. Newcomer KL, Martinez-Silvestrini JA, Schaefer MP, Gay RE, Arendt KW. Sensitivity of the Patient-rated Forearm Evaluation Questionnaire in lateral epicondylitis. J Hand Ther. 2005;18:400406. http://dx.doi.org/10.1197/j.jht.2005.07.001

25. Ng GY, Chan HL. The immediate effects of tension of counterforce forearm brace on neuromuscular performance of wrist exten- 
sor muscles in subjects with lateral humeral epicondylosis. J Orthop Sports Phys Ther. 2004;34:72-78. http://dx.doi.org/10.2519/ jospt.2004.34.2.72

26. Paungmali A, O'Leary S, Souvlis T, Vicenzino B. Hypoalgesic and sympathoexcitatory effects of mobilization with movement for lateral epicondylalgia. Phys Ther. 2003;83:374-383.

27. Portney LG, Watkins MP. Foundations of Clinical Research: Applications to Practice. 2nd ed. Upper Saddle River, NJ: Prentice Hall Health; 2000.

28. Rineer CA, Ruch DS. Elbow tendinopathy and tendon ruptures: epicondylitis, biceps and triceps ruptures. J Hand Surg Am. 2009;34:566-576. http://dx.doi.org/10.1016/j. jhsa.2009.01.022

29. Rompe JD, Overend TJ, MacDermid JC. Validation of the Patient-rated Tennis Elbow Evaluation Questionnaire. J Hand Ther. 2007;20:3-10; quiz 11. http://dx.doi.org/10.1197/j.jht.2006.10.003

30. Roquelaure $\mathrm{Y}, \mathrm{Ha} \mathrm{C}$, Leclerc $\mathrm{A}$, et al. Epidemiologic surveillance of upper-extremity musculoskeletal disorders in the working population. Arthritis Rheum. 2006;55:765-778. http://dx.doi. org/10.1002/art.22222

31. Russell TG, Jull GA, Wootton R. Can the Internet be used as a medium to evaluate knee angle? Man Ther. 2003;8:242-246.

32. Shamsoddini A, Hollisaz MT, Hafezi R, Amanellahi A. Immediate effects of counterforce forearm brace on grip strength and wrist extension force in patients with lateral epicondylosis. Hong Kong J Occup Ther. 2010;20:8-12. http:// dx.doi.org/10.1016/S1569-1861(10)70052-8

33. Shiri R, Varonen $H$, Heliövaara M, ViikariJuntura E. Hand dominance in upper extremity musculoskeletal disorders. J Rheumatol. 2007;34:1076-1082.

34. Snyder-Mackler L, Epler M. Effect of standard and Aircast tennis elbow bands on integrated electromyography of forearm extensor musculature proximal to the bands. Am J Sports Med. 1989;17:278-281

35. Stratford PW, Levy DR, Gowland C. Evaluative properties of measures used to assess patients with lateral epicondylitis at the elbow. Physiother Can. 1993;45:160-164.

36. Struijs PA, Smidt N, Arola H, van Dijk CN, Buchbinder R, Assendelft WJ. Orthotic devices for the treatment of tennis elbow. Cochrane Database Syst Rev. 2002:CD001821. http://dx.doi. org/10.1002/14651858.CD001821

37. Takasaki H, Aoki M, Muraki T, Uchiyama E, Murakami G, Yamashita T. Muscle strain on the radial wrist extensors during motion-simulating stretching exercises for lateral epicondylitis: a cadaveric study. J Shoulder Elbow Surg. 2007;16:854-858. http://dx.doi.org/10.1016/j. jse.2007.03.022

38. Takasaki H, Aoki M, Oshiro S, et al. Strain reduction of the extensor carpi radialis brevis tendon proximal origin following the application of a forearm support band. J Orthop Sports Phys Ther. 2008;38:257-261. http://dx.doi. org/10.2519/jospt.2008.2672

39. Verhaar JA. Tennis elbow. Anatomical, epidemiological and therapeutic aspects. Int Orthop. 1994;18:263-267.

40. Vicenzino B, Brooksbank J, Minto J, Offord S, Paungmali A. Initial effects of elbow taping on pain-free grip strength and pressure pain threshold. J Orthop Sports Phys Ther. 2003;33:400-407. http://dx.doi.org/10.2519/ jospt.2003.33.7.400

41. Wadsworth C, Nielsen DH, Burns LT, Krull JD, Thompson CG. Effect of the counterforce armband on wrist extension and grip strength and pain in subjects with tennis elbow. J Orthop Sports Phys Ther. 1989;11:192-197. http://dx.doi. org/10.2519/jospt.1989.11.5.192
42. Wainner RS, Fritz JM, Irrgang JJ, Boninger $\mathrm{ML}$, Delitto A, Allison S. Reliability and diagnostic accuracy of the clinical examination and patient self-report measures for cervical radiculopathy. Spine (Phila Pa 1976). 2003;28:52-62. http://dx.doi.org/10.1097/01. BRS.0000038873.01855.50

43. Walker-Bone K, Palmer KT, Reading I, Coggon D, Cooper C. Occupation and epicondylitis: a population-based study. Rheumatology (0xford). 2012;51:305-310. http://dx.doi.org/10.1093/ rheumatology/ker228

44. Walker-Bone K, Palmer KT, Reading I, Coggon D, Cooper C. Prevalence and impact of musculoskeletal disorders of the upper limb in the general population. Arthritis Rheum. 2004;51:642-651. http://dx.doi.org/10.1002/ art.20535

45. Walther M, Kirschner S, Koenig A, Barthel T, Gohlke F. Biomechanical evaluation of braces used for the treatment of epicondylitis. J Shoulder Elbow Surg. 2002;11:265-270. http://dx.doi. org/10.1067/mse.2002.122623

46. Walton MJ, Mackie K, Fallon M, et al. The reliability and validity of magnetic resonance imaging in the assessment of chronic lateral epicondylitis. J Hand Surg Am. 2011;36:475-479. http://dx.doi.org/10.1016/j.jhsa.2010.11.040

47. Wright $A$, Thurnwald $P, O^{\prime}$ Callaghan J, Smith J, Vicenzino B. Hyperalgesia in tennis elbow patients. J Musculoskelet Pain. 1994;2:83-97.

48. Wuori JL, Overend TJ, Kramer JF, MacDermid J. Strength and pain measures associated with lateral epicondylitis bracing. Arch Phys Med Rehabil. 1998;79:832-837.
MORE INFORMATION WWW.JOSPT.ORG

\section{NOTIFY JOSPT of Changes in Address}

Please remember to let $J O S P T$ know about changes in your mailing address.

The US Postal Service typically will not forward second-class periodical mail. Journals are destroyed, and the USPS charges JOSPT for sending them to the wrong address. You may change your address online at www.jospt.org. Visit Info Center for Readers, click Change of Address, and complete the online form. We appreciate your assistance in keeping JOSPT S mailing list up to date. 